\title{
The effect of vibrato on the recognition of masked vowels
}

\author{
LAURENT DEMANY and CATHERINE SEMAL \\ Université de Bordeaux II, Bordeaux, France
}

\begin{abstract}
Five experiments on the identifiability of synthetic vowels masked by wideband sounds are reported. In each experiment, identification thresholds (signal/masker ratios, in decibels) were measured for two versions of four vowels: a vibrated version, in which F0 varied sinusoidally around $100 \mathrm{~Hz}$; and a steady version, in which F0 was fixed at $100 \mathrm{~Hz}$. The first three experiments were performed on naive subjects. Experiment 1 showed that for maskers consisting of bursts of pink noise, vibrato had no effect on thresholds. In Experiment 2, where the maskers were periodic pulse trains with an F0 randomly varied between 120 and $140 \mathrm{~Hz}$ from trial to trial, vibrato slightly improved thresholds when the sound pressure level of the maskers was $40 \mathrm{~dB}$, but had no effect for 65-dB maskers. In Experiment 3, vibrated rather than steady pulse trains were used as maskers; when these maskers were at $40 \mathrm{~dB}$, the vibrated versions of the vowels were slightly less identifiable than their steady versions; but, as in Experiment 2, vibrato had no effect when the maskers were at $65 \mathrm{~dB}$. Experiment 4 showed that the unmasking effect of vibrato found in Experiment 2 disappeared in subjects trained in the identification task. Finally, Experiment 5 indicated that in trained listeners, vibrato had no influence on identification performance even when the maskers and the vowels had synchronous onsets and offsets. We conclude that vibrating a vowel masked by a wideband sound can affect its identification threshold, but only for tonal maskers and in untrained listeners. This effect of vibrato should probably be considered as a Gestalt phenomenon originating from central auditory mechanisms.
\end{abstract}

Opera singers, as well as other professional singers, make systematic use of vibrato in their performances: The fundamental frequency (F0) of most of their sustained tones is not steady, but rather oscillates around the target note. According to Seashore (1938/1967, chap. 4) and Horii (1989), vocal vibrato has an average modulation rate of $5-7 \mathrm{~Hz}$, and its typical extent is about 1 semitone (corresponding to a $6 \%$ frequency swing). It has been frequently hypothesized that, aside from expressive purposes, vibrato serves several sensory constraints (see Sundberg, 1977, 1982). For instance, vibrato might be used to reduce the demands on accuracy of F0. It might also be used to "trace out" the spectral envelope of a sung vowel, thus improving its intelligibility (McAdams, 1984; McAdams \& Rodet, 1988). In the present study, we focused on another possible effect of vibrato: its potential unmasking of vowels that are produced when another wideband sound is simultaneously present.

This work was supported by a grant from the Centre National d'Etude des Télécommunications (Convention 88-7B-7909245). Part of it was performed at the Laboratoire de Psychologie Experimentale, Université René Descartes, Paris. We wish to thank Christel Sorin, Stephen McAdams, Robert Carlyon, David Green, and Chris Darwin for discussions and/or comments on a previous version of the typescript. Special thanks are due to Jean-Luc Schwartz for his help in the synthesis of the vowels. The first author is affiliated with the Centre National de la Recherche Scientifique and the Laboratoire d'Audiologie Experimentale, INSERM U.229, Bordeaux. Correspondence may be addressed to Laurent Demany, Laboratoire de Psychoacoustique, Université de Bordeaux II, 146 rue Léo-Saignat, F-33076 Bordeaux, France.
Consider a steady vowel produced in the presence of another steady, periodic wideband sound, with a different F0. Vibrating the vowel may unmask it and improve its intelligibility through at least two possible auditory mechanisms.

First, an unmasking effect of vibrato could be simply due to the frequency selectivity of auditory masking, which originates from cochlear mechanics: In a periodically frequency-modulated vowel, the frequency of each partial varies with time; thus, its distance from a neighboring partial of a steady masker may, for some phase of the modulation cycle, be larger than when there is no vibrato; this should tend to make the vowel partial more detectable.

Second, an unmasking benefit of vibrato might rest on the exploiting of Gestalt factors at a central level of the auditory system. In the presence of a masking sound, a vowel component may not be identified as such even when it is actually detectable-that is, when its removal would produce an audible change in the stimulus. However, with vibrato, its identification as a vowel component may be favored by Gestalt factors. In a steady spectral background, the Gestalt rule of similarity may promote the perceptual segregation of frequency-modulated spectral components; also, the fact that the partials of a vibrated vowel move on parallel paths in the frequency domain may favor their central grouping into a single sound image according to the rule of common fate. As well as individual partials that are resolved in the auditory periphery, sets of adjacent and unresolved partials of the vowel 
(i.e., formants distant from its F0) could be grouped on these bases.

The first mechanism is certainly operative in at least some conditions - that is, for some spectral relationships between the vowel and the masker and for some types of vibrato. However, the existence of the second mechanism is presently questionable; it has never been proved by measuring and comparing identification performances.

From experiments in which the stimuli were simultaneous nonspeech sounds and subjects' responses consisted of introspective judgments regarding the number of sounds they heard, McAdams (1984) and Chalikia and Bregman (1989) suggested that the rule of common fate is operative in the frequency domain (see also Bregman \& Doehring, 1984). However, this suggestion has not been corroborated by related experiments in which vowels rather than nonspeech sounds were used (Chalikja \& Bregman, 1989; Gardner \& Darwin, 1986; Gardner, Gaskill, \& Darwin, 1989; Marin \& McAdams, in press; McAdams, 1989). The studies of McAdams (1989) and Marin and McAdams (in press) indicate that in a mixture of simultaneous vowels with different F0s, a given vowel is judged as being more "prominent" when vibrated than when steady; but even when the other vowels in the mixture are also vibrated (in the same manner or differently)that is, even when vibrato does not provide distinctive similarity or common fate cues. These studies failed to demonstrate that vibrato can make a masked vowel more prominent through Gestalt cues. Chalikia and Bregman (1989) used an identification task instead of requiring prominence judgments, and their modulations consisted of glissandi rather than periodic oscillations; but their data are basically consistent with those of McAdams (1989) and Marin and McAdams (in press). They found that when two simultaneous vowels sweep in pitch along crossing paths, the vowels are not identified significantly better than when they sweep along parallel paths; yet common fate cues are available in the case of crossing paths but not in the case of parallel paths. Finally, Gardner and Darwin (1986) and Gardner et al. (1989) concluded from their experiments on the recognition of isolated syllables with vibrated formants that the common fate rule is not used to group together frequency-modulated spectral components into speech categories.

We report here five experiments designed to assess the effect of vibrato on the identifiability of vowels masked by wideband nonspeech sounds. Masking sounds of several types were used, and the overall sound pressure level (SPL) was also an independent variable. An additional independent variable was the subjects' training in the identification task.

\section{EXPERIMENT 1}

In Experiment 1, the masker was a pink noise. A pink noise is spectrally - and perceptually-quite different from a voiced vowel. Thus, when such a masker is used, it is unlikely that optimal effects of unmasking through vibrato will be found. But Experiment 1 actually served as a control experiment: In order to demonstrate that a given vowel can become unmasked if it is vibrated, it is necessary to check that the vibrato used does not improve the vowel identifiability independently of the masking context; this is verified if the steady and vibrated versions of the vowel appear to be equally identifiable in the presence of the same masker.

\section{Method}

Stimuli. Four french vowels, $/ \mathrm{i} /, / \mathrm{y} /, / \mathrm{e} /$, and $/ \mathrm{d} /$, were digitally synthesized by means of tables ( 512 16-bit samples per table) representing their respective periods. Each table was constructed by adding 40 harmonically related sine components in sine phase (synchronous positive-going zero crossings). Each vowel's power spectrum is shown in Figure 1 . It is important to note that Partials 1-13 had exactly the same relative levels in $/ i /$ and $/ y /$, as well as Partials $1-7$ in /e/ and / $/$. The four spectra belong to the corpus used by Schwartz and Escudier (1989) in their experiments on vowel perception.

Each vowel was produced with two different intonations: a steady version and a vibrated version. In the steady version, F0 was $100 \mathrm{~Hz}$; in the vibrated version, F0 varied sinusoidally, at a rate of $6 \mathrm{~Hz}$, between 97 and $103 \mathrm{~Hz}$. In the vibrated vowels, partials maintained harmonic relationships and were not modulated in amplitude (which implies that the formant frequencies were modulated in the same way as F0). All vowels had a total duration of $800 \mathrm{msec}$ and rise/fall times of $100 \mathrm{msec}$, which were shaped with a raised cosine function. They were generated in real time by a DMX-1000 synthesizer, under the control of a microcomputer (Northstar Horizon), with a sampling rate of $50 \mathrm{kHz}$, and through a 16-bit D/A converter. Foldover was prevented by low-pass filtering with a cutoff frequency of $9.6 \mathrm{kHz}$. The SPL of each vowel, which varied adaptively during the test sessions (see Procedure), was controlled by means of a programmable attenuator (Charybdis).

The masking pink noise was produced by a Brüel \& Kjaer ana$\log$ noise generator. Its only filtering was that caused by the TDH-49 earphone to which bursts of this noise, mixed with a vowel, were led. All stimuli were delivered to the subjects' right ear only. On each experimental trial, the output of the noise generator, working on line, was abruptly gated on $500 \mathrm{msec}$ before the vowel onset, and abruptly gated off $100 \mathrm{msec}$ after the vowel offset (see Figure 2a). The SPL of the noise bursts was 40 or $65 \mathrm{~dB}$.

Procedure. Subjects were individually tested in a soundproof booth where they were seated in front of a response box with four buttons respectively labeled $i, u, e ́$, and e. These labels represent the standard French orthography for the vowels used.

The experiment comprised two sessions. The first session began with a pretest assessing the subject's ability to identify the 8 vowels ( 4 vowel categories $\times 2$ intonations) in the absence of any masking sound. During this pretest, 80 stimuli consisting of 10 exemplars of each of the 8 vowels were presented in a random order, at $70 \mathrm{~dB}$ SPL. Subjects had to label each stimulus by pressing the appropriate button of the response box. They were informed before the pretest that the stimuli included steady as well as vibrated vowels. Response time was unlimited and no feedback was provided. Each response was followed by the presentation of the next stimulus after a 600 -msec delay. If the subject made more than three errors in the pretest, it was repeated immediately (see Subjects).

The second part of the first session and the entire second session each consisted of 400 identification trials in which the stimuli were 50 exemplars of each of the 8 vowels, accompanied by bursts of pink noise as described in the previous section. The only procedural 

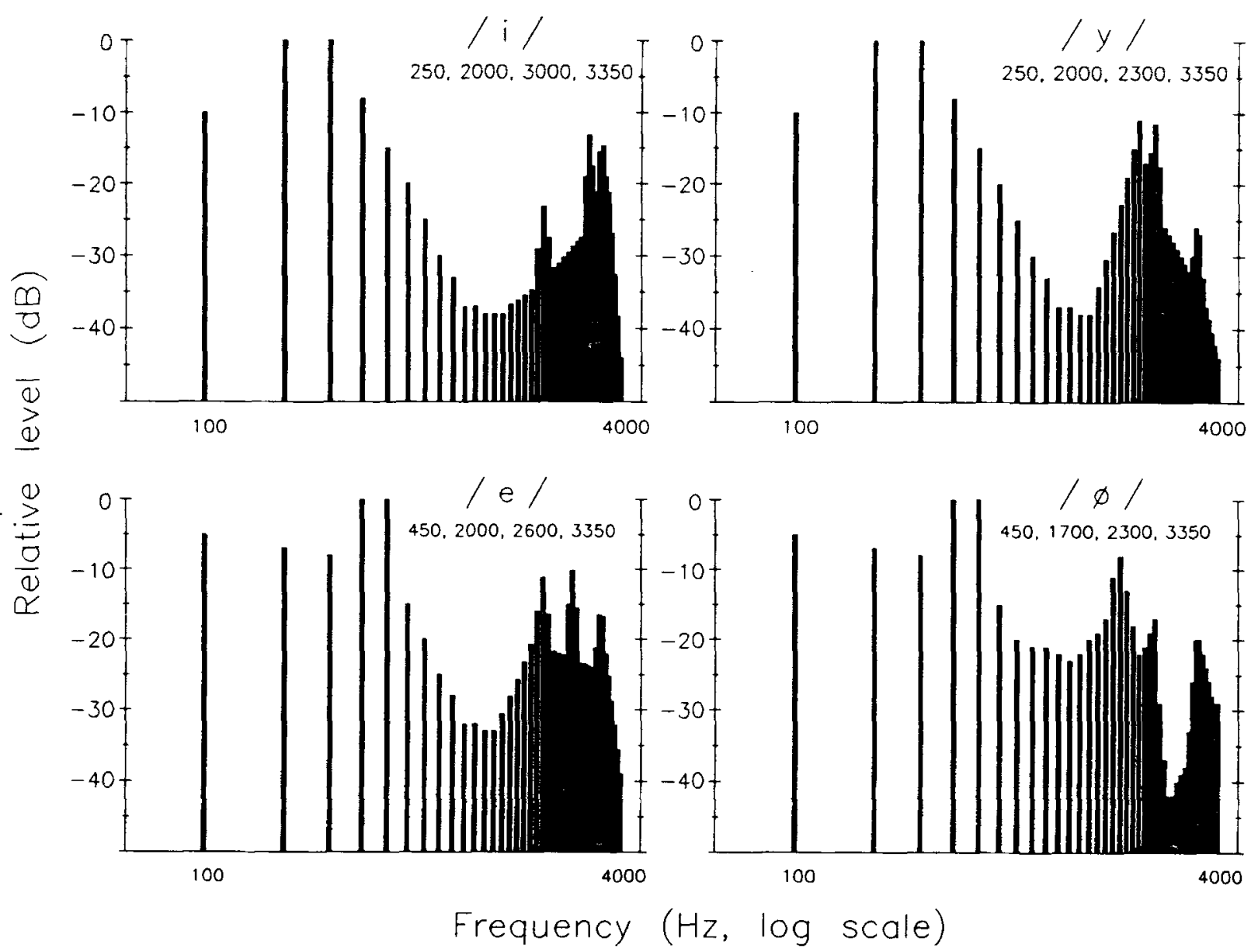

Figure 1. Power spectrum of the four steady vowels used. The numbers indicated above each spectrum are the vowel's formant frequencies in hertz.

difference between these two trial blocks was the level of the noise bursts, $40 \mathrm{~dB}$ in one block and $65 \mathrm{~dB}$ in the other; the 40- $\mathrm{dB}$ level was used in the first block for one half of the subjects, and in the second block for the other half.

During each trial block, the 400 stimuli were presented in a random order (renewed from block to block), and the level of each of the eight vowels varied from trial to trial according to an independent adaptive staircase. Any trial block thus consisted of eight independent and intermixed adaptive staircases. In each staircase, the level of the vowel was initially $10 \mathrm{~dB}$ below the noise level, decreased by $2 \mathrm{~dB}$ after two consecutive correct responses, and increased by $2 \mathrm{~dB}$ after an incorrect response. The maximum level of any vowel was $92 \mathrm{~dB}$ SPL, and the subject's data were automatically rejected if this level was reached. As in the pretest, response time was unlimited and no feedback was provided. Any response was followed by the next trial (i.e., the onset of the next noise burst) after a 200-msec delay. After the 100th, 200th, and 300th trial of each block, the subject was informed by the computer screen that it was permissible to rest, and to come out of the booth for a few minutes. The subjects were instructed to avoid always selecting the same response on trials in which they felt completely unable to identify the presented vowel.

Subjects. Thirteen adult listeners, unaware of the tested hypothesis and unfamiliar with the task, most of whom were native speakers (a)
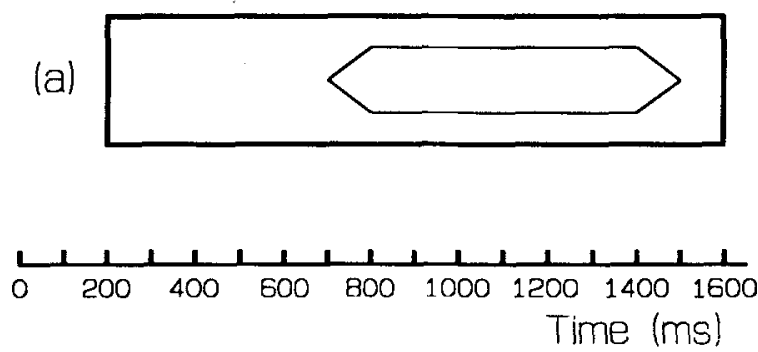

(b)

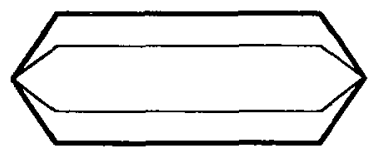

Figure 2. Timing of the stimuli within a trial in (a) Experiments 1-4 and (b) Experiment 5. The origin of the time axis is the moment of the subject's response on the previous trial. The vowel's temporal envelope is displayed within the masker's envelope, and by thinner lines. (The onset and ofiset ramps used in the experiments were not linear, as suggested by the figure, but shaped with a raised cosine function.) 
of French, served as subjects. The pretest had to be repeated for 3 of them; in the second pretest, 1 subject made only one error and the other 2 subjects made no errors at all. One subject's data were rejected during the experiment proper, because the level of a vowel had reached $92 \mathrm{~dB}^{1}$; the data analyzed below thus come from 12 subjects.

\section{Results}

Confusion matrix. The subjects' errors in the experiment proper are described in Table 1. This overall confusion matrix is the average of four partial matrices, respectively derived from the data obtained for the two intonation types and the two masker levels. We averaged these four matrices because they were very similar: For each masker level, the correlation between the matrices obtained for the steady and vibrated vowels exceeded 0.990 ; in addition, the correlation between the two mean matrices respectively obtained for the $40-$ and $65-\mathrm{dB}$ maskers was 0.966 .

Table 1 shows that $/ \mathrm{i} /$ was mainly mistaken for $/ \mathrm{y} /, / \mathrm{y} /$ for $/ \mathrm{i} /, / \mathrm{e} /$ for $/ \boldsymbol{\sigma} /$, and $/ ø /$ for $/ \mathrm{e} /$. This indicates that it was perceptually more difficult to locate the vowels' second and/or higher formants than to locate their first formants.

Identification thresholds. For each of the eight vowels presented in a given trial block, a "threshold" was computed by averaging the reversal points in the variation of its level. The first two reversal points were excluded from

Table 1

Confusion Matrices Derived from the Data of Experiments 1-5

\begin{tabular}{|c|c|c|c|c|}
\hline \multirow[b]{2}{*}{$\underline{\text { Stimulus }}$} & \multicolumn{4}{|c|}{ Response } \\
\hline & "i" & "y" & "e" & $"$ "ø" \\
\hline \multicolumn{5}{|c|}{ Experiment 1} \\
\hline$/ \mathrm{i} /$ & & 79.8 & 9.9 & 10.3 \\
\hline$/ y /$ & 43.3 & & 23.3 & 33.3 \\
\hline$/ \mathbf{e} /$ & 8.2 & 13.6 & & 78.1 \\
\hline$/ d /$ & 9.7 & 30.5 & 59.7 & \\
\hline \multicolumn{5}{|c|}{ Experiment 2} \\
\hline /i/ & & 90.6 & 4.6 & 4.8 \\
\hline$/ y /$ & 71.0 & & 13.4 & 15.7 \\
\hline$/ \mathrm{e} /$ & 3.5 & 9.0 & & 87.5 \\
\hline$/ \varnothing /$ & 12.1 & 16.4 & 71.4 & \\
\hline \multicolumn{5}{|c|}{ Experiment 3} \\
\hline$/ \mathrm{i} /$ & & 72.2 & 13.9 & 13.8 \\
\hline$/ y /$ & 53.9 & & 18.5 & 27.5 \\
\hline le/ & 7.7 & 11.5 & & 80.7 \\
\hline 101 & 14.0 & 22.0 & 64.1 & \\
\hline \multicolumn{5}{|c|}{ Experiment 4} \\
\hline /i/ & & 78.7 & 8.6 & 12.8 \\
\hline$/ \mathrm{y} /$ & 77.8 & & 6.8 & 15.4 \\
\hline lef & 8.2 & 7.3 & & 84.6 \\
\hline 101 & 23.5 & 25.9 & 50.7 & \\
\hline \multicolumn{5}{|c|}{ Experiment 5} \\
\hline /i/ & & 72.7 & 12.7 & 14.5 \\
\hline$/ \mathrm{y} /$ & 83.5 & & 5.0 & 11.5 \\
\hline le/ & 8.0 & 6.4 & & 85.6 \\
\hline 101 & 23.4 & 18.7 & 57.9 & \\
\hline
\end{tabular}

Note-Each entry is a percentage computed from the distribution of errors for a given stimulus vowel (steady and vibrated versions combined). the averaging process, as well as the last one if the total number of reversal points was uneven. Given the levelvariation rules selected, the threshold of a vowel was an estimation of the level for which the probability of a correct identification of this vowel was 0.707 . In the following, thresholds will always be expressed in decibels re the masker level rather than in decibels SPL.

Table 2 (first two rows) shows the identification thresholds obtained in the experiment, averaged across subjects. These thresholds were submitted to an overall ANOVA (12 subjects $\times 2$ masker levels $\times 4$ vowel categories $\times$ 2 intonations), which revealed a marginally significant main effect of masker level $[F(1,11)=4.56, .05<$ $p<.10$ ], a significant main effect of vowel category $[F(3,33)=14.26, p<.005]$, and a significant interaction of masker level with vowel category $[F(3,33)=3.02$, $p<.05]{ }^{2}$ The chief finding is the absence of any reliable effect of intonation $[F(1,11)=0.45]$.

\section{EXPERIMENT 2}

In Experiment 2, we replaced the bursts of pink noise serving as maskers in Experiment 1 with bursts of steady periodic tones. This was the only difference between the two experiments.

\section{Method}

Maskers. The maskers, essentially pulse trains, were obtained by adding the first 50 harmonics of some $\mathrm{F0}$ at equal amplitudes and in sine phase. On each trial, as in Experiment 1, a masker was abruptly gated on $500 \mathrm{msec}$ before the vowel onset and abruptly gated off $100 \mathrm{msec}$ after the vowel offset, and its level was 40 or $65 \mathrm{~dB}$ SPL. The maskers were generated in real time through one $\mathrm{D} / \mathrm{A}$ converter of the DMX-1000 synthesizer, the other converter producing the vowels. The sampling rate of the stimuli was $34.7 \mathrm{kHz}$. The F0 of the maskers was steady within each trial, but it varied randomly from trial to trial; its possible values, extracted from a rectangular probability distribution, ranged from 120 to $140 \mathrm{~Hz}$-that is, from 3.2 to 5.8 semitones above the F0 of the steady vowels, $100 \mathrm{~Hz}$. Note that, according to Scheffers (1983, chap. 4), two simultaneous and steady vowels can be better identified if they have different F0s than if they have the same F0, but a ceiling effect is reached for an F0 difference of about 1 semitone. Thus, in Experiment 2, the minimum difference between the vowels' F0 and the maskers' F0 was markedly larger than the critical difference found by Scheffers.

Subjects. Fifteen new naive listeners participated in the experiment. In the pretest, all reached the criterion performance immediately. However, 3 subjects had to be rejected in the experiment proper, either because the level of a vowel reached $92 \mathrm{~dB}$ ( 2 cases) or because there was only one reversal point in the level variation of a vowel ( 1 case). The data analyzed below thus bear on 12 subjects.

\section{Results}

Confusion matrix. The subjects' errors in Experiment 2 are described in Table 1 . This overall confusion matrix is, again, the average of four partial matrices, respectively derived from the data obtained for the two intonation types and the two masker levels. For each masker level, the correlation between the two matrices respectively obtained for the steady and vibrated vowels 
Table 2

Average Identification Thresholds of the Vowels in Each Experiment

\begin{tabular}{|c|c|c|c|c|c|c|c|c|c|c|c|c|}
\hline & \multicolumn{5}{|c|}{ Steady Vowels } & \multicolumn{5}{|c|}{ Vibrated Vowels } & \multicolumn{2}{|c|}{$\begin{array}{l}\text { Threshold } \\
\text { Difference }\end{array}$} \\
\hline & /i/ & $/ \mathrm{y} /$ & $\mid \mathbf{e} /$ & $|\boldsymbol{g}|$ & $M$ & $/ \mathbf{i} /$ & $/ y /$ & $/ \mathrm{e} /$ & $/ ø /$ & $M$ & $M$ & $S D$ \\
\hline \multicolumn{13}{|c|}{ Experiment 1} \\
\hline $\begin{array}{l}\text { 40-dB masker } \\
65-\mathrm{dB} \text { masker }\end{array}$ & $\begin{array}{l}-6.4 \\
-7.2\end{array}$ & $\begin{array}{r}-9.6 \\
-11.1\end{array}$ & $\begin{array}{l}-7.0 \\
-8.9\end{array}$ & $\begin{array}{l}-10.0 \\
-10.3\end{array}$ & $\begin{array}{l}-8.2 \\
-9.4\end{array}$ & $\begin{array}{l}-6.5 \\
-7.0\end{array}$ & $\begin{array}{r}-9.2 \\
-11.0\end{array}$ & $\begin{array}{l}-7.3 \\
-8.7\end{array}$ & $\begin{array}{r}-10.6 \\
-8.6\end{array}$ & $\begin{array}{l}-8.4 \\
-8.8\end{array}$ & $\begin{array}{r}0.2 \\
-0.6\end{array}$ & $\begin{array}{l}0.6 \\
1.8\end{array}$ \\
\hline \multicolumn{13}{|c|}{ Experiment 2} \\
\hline $\begin{array}{l}\text { 40-dB maskers } \\
65-\mathrm{dB} \text { maskers }\end{array}$ & $\begin{array}{r}-4.0 \\
-11.5\end{array}$ & $\begin{array}{l}-10.7 \\
-17.2\end{array}$ & $\begin{array}{r}-6.4 \\
-12.5\end{array}$ & $\begin{array}{r}-9.1 \\
-16.8\end{array}$ & $\begin{array}{r}-7.5 \\
-14.5\end{array}$ & $\begin{array}{r}-5.1 \\
-11.8\end{array}$ & $\begin{array}{l}-10.9 \\
-17.4\end{array}$ & $\begin{array}{r}-7.1 \\
-13.1\end{array}$ & $\begin{array}{l}-11.6 \\
-14.0\end{array}$ & $\begin{array}{r}-8.7 \\
-14.1\end{array}$ & $\begin{array}{r}1.2 \\
-0.4\end{array}$ & $\begin{array}{l}1.2 \\
1.3\end{array}$ \\
\hline \multicolumn{13}{|c|}{ Experiment 3} \\
\hline $\begin{array}{l}\text { 40-dB maskers } \\
65-\mathrm{dB} \text { maskers }\end{array}$ & $\begin{array}{r}-3.0 \\
-11.2\end{array}$ & $\begin{array}{r}-7.4 \\
-15.7\end{array}$ & $\begin{array}{r}-5.9 \\
-12.3\end{array}$ & $\begin{array}{l}-11.1 \\
-17.1\end{array}$ & $\begin{array}{r}-6.8 \\
-14.1\end{array}$ & $\begin{array}{r}-3.3 \\
-11.2\end{array}$ & $\begin{array}{r}-7.2 \\
-15.2\end{array}$ & $\begin{array}{r}-4.9 \\
-12.2\end{array}$ & $\begin{array}{r}-8.4 \\
-16.8\end{array}$ & $\begin{array}{r}-5.9 \\
-13.9\end{array}$ & $\begin{array}{l}-0.9 \\
-0.2\end{array}$ & $\begin{array}{l}1.4 \\
0.9\end{array}$ \\
\hline \multicolumn{13}{|c|}{ Experiment 4} \\
\hline $\begin{array}{l}\text { Subject } 1 \\
\text { Subject } 2 \\
\text { Subject } 3\end{array}$ & $\begin{array}{l}-11.7 \\
-12.0 \\
-15.9\end{array}$ & $\begin{array}{l}-12.3 \\
-13.6 \\
-13.7\end{array}$ & $\begin{array}{r}-11.5 \\
-9.4 \\
-17.2\end{array}$ & $\begin{array}{l}-18.7 \\
-19.5 \\
-12.6\end{array}$ & $\begin{array}{l}-13.5 \\
-13.6 \\
-14.8\end{array}$ & $\begin{array}{l}-11.6 \\
-11.0 \\
-16.2\end{array}$ & $\begin{array}{l}-12.5 \\
-13.8 \\
-13.4\end{array}$ & $\begin{array}{l}-11.0 \\
-10.5 \\
-17.9\end{array}$ & $\begin{array}{l}-20.0 \\
-19.3 \\
-14.0\end{array}$ & $\begin{array}{l}-13.8 \\
-13.6 \\
-15.4\end{array}$ & $\begin{array}{l}0.3 \\
0.0 \\
0.6\end{array}$ & \\
\hline \multicolumn{13}{|c|}{ Experiment 5} \\
\hline $\begin{array}{l}\text { Subject } 1 \\
\text { Subject } 2 \\
\text { Subject } 3\end{array}$ & $\begin{array}{l}-11.7 \\
-11.2 \\
-14.4\end{array}$ & $\begin{array}{l}-11.5 \\
-11.2 \\
-10.1\end{array}$ & $\begin{array}{r}-7.5 \\
-11.1 \\
-14.1\end{array}$ & $\begin{array}{l}-18.0 \\
-15.3 \\
-10.7\end{array}$ & $\begin{array}{l}-12.2 \\
-12.2 \\
-12.3\end{array}$ & $\begin{array}{l}-11.2 \\
-11.9 \\
-13.7\end{array}$ & $\begin{array}{r}-11.2 \\
-11.2 \\
-9.8\end{array}$ & $\begin{array}{r}-8.1 \\
-11.2 \\
-14.4\end{array}$ & $\begin{array}{l}-18.7 \\
-15.9 \\
-10.8\end{array}$ & $\begin{array}{l}-12.3 \\
-12.5 \\
-12.2\end{array}$ & $\begin{array}{r}0.1 \\
0.3 \\
-0.1\end{array}$ & \\
\hline
\end{tabular}

Note-Thresholds are expressed in decibels with reference to the masker level. Positive threshold differences in the penultimate column indicate favorable effects of vibrato.

exceeded 0.996 . In addition, the correlation between the mean matrices respectively obtained for the 40 - and $65-\mathrm{dB}$ maskers was 0.980 .

Table 1 shows that the subjects' main errors were again confusions between $/ \mathrm{i} /$ and $/ \mathrm{y} /$ and between $/ \mathrm{e} /$ and $/ \varnothing /$. These confusions predominate even more than in Experiment 1 , which indicates that locating the vowels' second and/or higher formants was a relatively more important perceptual problem in Experiment 2 than it was in Experiment 1 . This can be explained by the difference between the spectral envelopes of the maskers used in the two experiments. The auditory scale of frequency is approximately logarithmic; thus, for the ear, the spectrum of a pink noise is approximately flat, whereas a pulse train contains more power at high frequencies (in the region of the second and higher formants of vowels) than at low frequencies.

Identification thresholds. The subjects' identification thresholds were submitted to an overall ANOVA, identical in design to the ANOVA performed in Experiment 1. Significant main effects were found for masker level $[F(1,11)$ $=101.19, p<.001]$ and vowel category $[F(3,33)=$ $7.95, p<.001]$, but not intonation $[F(1,11)=1.47$, $p>.10]$. However, the interaction of intonation with masker level was significant $[F(1,11)=13.06, p<$ $.005]$, as was the three-way interaction $[F(3,33)=6.21$, $p<.005]$.

Table 2 indicates that, when expressed relative to the level of the maskers, thresholds were much poorer for the 40- $\mathrm{dB}$ maskers than for the 65- $\mathrm{dB}$ maskers; on the average, this level effect amounts to $6.2 \mathrm{~dB}$. A similar trend had been found in Experiment 1, but it was definitely weaker. However, note that similar mean thresholds (near $-8 \mathrm{~dB}$ ) were found for the $40-\mathrm{dB}$ maskers of Experiments 1 and 2.

Given the significant interaction of intonation and masker level, two additional ANOVAs were performed, each bearing on the data collected for a given value of the masker level. These additional ANOVAs revealed that intonation had a significant effect when the masker level was $40 \mathrm{~dB}[F(1,11)=10.59, p=.0077]$, but not when the masker level was $65 \mathrm{~dB}[F(1,11)=1.26, p>.10]$. The interaction of intonation with vowel category was not significant for the $40-\mathrm{dB}$ maskers $[F(3,33)=1.14$, $p>.10]$, but it was significant for the $65-\mathrm{dB}$ maskers $[F(3,33)=3.42, p<.05]$.

Table 2 shows that the significant main effect of intonation for the 40-dB maskers consists of a 1.2- $\mathrm{dB}$ mean unmasking by vibrato. For the $65-\mathrm{dB}$ maskers, the significant interaction of intonation with vowel category reflects a difference between $/ ø /$ and the other three vowels: Vibrato has a deleterious effect on performance in the case of $/ \varnothing /$ and essentially no effect in the case of the other vowels.

\section{EXPERIMENT 3}

The results of Experiment 2 are somewhat surprising: Why did vibrato favor identification performance only for the 40-dB maskers? The aim in Experiment 3 was to check that this positive effect of vibrato obtained with the low-level maskers was due to the intonation difference between the vibrated vowels and the maskers rather than to vibrato per se. Suppose that the (steady) maskers used in Experiment 2 are replaced by maskers that are vibrated in exactly the same way as the vibrated versions 
of the vowels. With such maskers, the steady versions of the vowels should be identified better than their vibrated versions if the effect found in Experiment 2 was really due to the intonation difference between maskers and vowels.

\section{Method}

Maskers. The only difference between the new maskers and those used in Experiment 2 was the frequency modulation of the new maskers: The F0 of each masker now varied sinusoidally, at a rate of $6 \mathrm{~Hz}$, between 0.97 and 1.03 times its central value (randomly selected between 120 and $140 \mathrm{~Hz}$, as in Experiment 2). Each vowel started 500 msec after the masker onset, as in Experiments 1 and 2 , but the frequency modulation of each vibrated vowel was always in phase with (i.e., parallel to) the frequency modulation of its masker. The sampling rate of the stimuli was $31.8 \mathrm{kHz}$.

Subjects. Fifteen listeners participated in Experiment 3. All reached the criterion performance immediately in the pretest, but 3 were excluded during the experiment proper because the level of a vowel reached $92 \mathrm{~dB}$. The final data thus bear on 12 subjects.

\section{Results}

Confusion matrix. Table 1 describes the subjects' errors. This overall confusion matrix is, again, the mean of four partial and very strongly correlated matrices, respectively derived for the two masker levels (40 vs. $65 \mathrm{~dB}$ ) and the two types of vowels (steady vs. vibrated).

Once more, confusions between $/ \mathrm{i} /$ and $/ \mathrm{y} /$ and between $/ \mathrm{e} /$ and $/ ø /$ predominated. However, the relative weight of these confusions in the overall set of errors was smaller than in Experiment 2, and closer to their relative weight in Experiment 1.

Identification thresholds. An overall ANOVA of the identification thresholds revealed significant main effects of masker level $[F(1,11)=53.64, p<.001]$ and vowel category $[F(3,33)=14.49, p<.001]$, and a marginally significant effect of intonation $[F(1,11)=4.49$, $p<.10$ ]. Table 2 shows that the effect of masker level was quite similar to the effect found in Experiment 2; thresholds were again much poorer for the $40-\mathrm{dB}$ maskers than for the 65- $\mathrm{dB}$ maskers.

A separate ANOVA performed on the thresholds obtained for the 40-dB maskers revealed a significant effect of both intonation $[F(1,11)=4.83, p=.050]$ and the interaction of intonation with vowel category $[F(3,33)=$ $2.95, p<.05]$. By contrast, a similar analysis performed on the data for the $65-\mathrm{dB}$ maskers did not reveal any of these effects $(F<1)$.

Table 2 indicates that for the $40-\mathrm{dB}$ maskers, the mean threshold of the steady vowels was better than the mean threshold of the vibrated vowels; the difference amounts to $0.9 \mathrm{~dB}$. Note also that the main contribution to this effect is provided by the vowel /ø/. In Experiment 2, /ø/ was also responsible for the major part of the intonation effect, although this effect was in the opposite direction.

It seems fair to conclude that the results of Experiments 2 and 3 are quite congruent. Experiment 3 confirmed that in Experiment 2, vibrato favored identifica- tion performance by virtue of the intonation difference between the vowels and the maskers. In addition, an effect of vibrato was found only for the 40-dB maskers in Experiment 3 as well as in Experiment 2.

\section{EXPERIMENT 4}

The previous three experiments were performed on naive subjects. The aim of Experiment 4 was to determine if the vibrato effect found in Experiment 2 would also be obtained in subjects trained in the identification task. Thus, Experiment 4 was essentially a replication of Experiment 2 on trained subjects. However, only 40-dB maskers were used, since no vibrato effect had been obtained for the 65-dB maskers in Experiment 2.

\section{Method}

Three subjects with normal hearing participated in Experiment 4. Subject 1 (age 35) and Subject 2 (age 30) were the authors. Subject 3 (age 22) was a psychology student, paid for her services. Subject 3 was not informed of the question raised in the experiment before its completion.

For each subject, Experiment 4 proper consisted of 10 trial blocks, methodologically identical in every respect to the trial blocks involving the $40-\mathrm{dB}$ maskers in Experiment 2. These 10 trial blocks were run by pairs, on five different days. They were preceded by a variable number of similar blocks, which were considered a posteriori as practice blocks and during which each subject's thresholds decreased. We believe that the mean thresholds reported below are good estimations (within 1 or $1.2 \mathrm{~dB}$ ) of subjects' asymptotic performances.

For each subject, the sessions run in the framework of Experiment 4 were intermixed with the sessions run in the framework of Experiment 5.

\section{Results}

Confusion matrix. The individual confusion matrices respectively obtained for the steady and vibrated vowels were strongly correlated $(r \geq .982)$. The overall confusion matrix is similar to the corresponding matrix in Experiment 2 (see Table 1); the correlation of these two matrices amounts to 0.943 .

Identification thresholds. The grand mean of subjects' thresholds was $-14.1 \mathrm{~dB}$, whereas the corresponding mean in Experiment 2 was $-8.1 \mathrm{~dB}$. We ascribe this 6$\mathrm{dB}$ difference to the present subjects' training rather than to uncommon properties of their auditory systems.

An overall ANOVA of the thresholds revealed significant main effects for subjects $[F(2,18)=17.11$, $p<.001]$ and vowel category $[F(3,27)=89.86$, $p<.001]$, but the effect of intonation only approached significance $[F(1,9)=3.42, .05<p<.10]$. The interaction of intonation and vowel category also approached significance $[F(3,27)=2.52, .05<p<.10]$, and there was no significant interaction of subjects and intonation $[F(2,18)=1.04, p>.10]$.

The mean threshold of each subject for each vowel is indicated in Table 2. Averaged over the 3 subjects, the effect of intonation amounts to only $0.3 \mathrm{~dB}$. The effect 
found in Experiment 2 was four times larger. We thus conclude that this effect virtually disappears in trained subjects.

\section{EXPERIMENT 5}

On each trial of the previous four experiments, the onset of the presented vowel was delayed by $500 \mathrm{msec}$ relative to the masker onset. Scheffers (1983, chap. 3) found that the identification threshold of a vowel masked by a burst of pink noise is about $4 \mathrm{~dB}$ lower when the onset of the noise burst precedes the vowel onset by $300 \mathrm{msec}$ than when the vowel and the noise burst are synchronous. It can be imagined that delaying the vowel onset not only improves its threshold, but also reduces or abolishes a benefit of vibrato that would exist only in the absence of onset delay. One possible explanation of Scheffers' finding is that an onset delay allows a perceptual comparison between the spectrum of the masker alone and the spectrum of the masker-plus-vowel aggregate, whereas suppressing the delay eliminates the information on the spectrum of the masker alone. ${ }^{3}$ In the absence of well-defined information on the masker alone, Gestalt cues provided by vibrating the vowel might help to locate its formants with a better efficiency than when the masker is well defined in advance. This hypothesis led us to replicate Experiment 4 with only one difference: the suppression of the onset and offset delays.

\section{Method}

Experiment 5 was identical to Experiment 4, except that, on each trial, the masker and the vowel were gated on and off simultaneously with 100 -msec raised cosine ramps (Figure $2 b$ ). The same 3 subjects were used in the two experiments, and the sessions nun in the framework of Experiment 5 were intermixed with those run in the framework of Experiment 4.

\section{Results}

Confusion matrix. The correlation of the confusion matrices respectively obtained for the steady and vibrated vowels was 0.995 for Subject 1, 0.965 for Subject 2, and 0.998 for Subject 3 . The overall confusion matrix is quite similar to the confusion matrix obtained from Experiment $4(r=0.990)$. (See Table 1.)

Identification thresholds. The grand mean of subjects' thresholds was $-12.3 \mathrm{~dB}$, which is $1.8 \mathrm{~dB}$ worse than the -14.1-dB grand mean found in Experiment 4. Thus, the suppression of the onset and offset delays degraded thresholds, but about half as much as expected on the basis of Scheffers' (1983) findings.

An overall ANOVA of the thresholds revealed significant effects for vowel category $[F(3,27)=27.68$, $p<.001]$ and the interaction of subjects with vowel category $[F(6,54)=20.30, p<.001]$, but also showed that subjects, intonation, and the interactions involving intonation were completely unsignificant sources of variance ( $F<1$ in each case). Indeed, it can be computed from Table 2 that, averaged over the 3 subjects, the effect of intonation amounts to not more than $0.1 \mathrm{~dB}$.
We conclude that for trained subjects and for the steady periodic maskers used in this research, vibrating a masked vowel does not improve its identification threshold even when the maskers and the vowels are gated on and off simultaneously.

\section{GENERAL DISCUSSION}

We found that vibrating a vowel masked by a wideband sound can slightly improve its identification threshold, but only under special conditions. An unmasking effect of vibrato was obtained: (1) when the maskers were pulse trains, but not when they were bursts of pink noise; (2) when the masking pulse trains had a steady F0, but not when they were modulated in the same way as the vibrated vowels; (3) when the SPL of the maskers was $40 \mathrm{~dB}$, but not when it was $65 \mathrm{~dB}$; (4) in naive listeners, but not in subjects trained in the identification task. These results raise two related questions: What is the mechanism of the vibrato effect found, and why did it occur only under such conditions? Let us begin by ruling out some inadequate answers to the former question.

First, the specific vibrato used did not induce an amplitude modulation of vowel partials, which could have increased the detectability of these partials. Such an amplitude modulation is induced when a vowel is vibrated while its spectral envelope is kept fixed. This was not the case in our experiments.

Second, the specific vibrato used did not favor the phonetic categorization of the vowels by making them more familiar, more similar to natural vowels. In other words, the positive effect of vibrato found in Experiment 2 was a purely sensory effect. The strongest evidence for this point lies in the results of Experiment 3, where vibrated maskers were used: With such maskers (at $40 \mathrm{~dB}$ ), it was found that the steady versions of the vowels were more identifiable than their vibrated versions.

Third, it is almost certain that the unmasking effect of vibrato found in Experiment 2 was not due to cochlear mechanics but is instead a central effect. One argument in favor of that view is that if the unmasking phenomenon was due to cochlear mechanics, it should have been observed on trained as well as untrained listeners. Another argument stems from the confusion matrix found in Experiment 2 . This matrix indicates that the subjects' crucial perceptual problem was to locate the second and/or higher formants of the vowels rather than their first formants. In the frequency region of the vowels' second and higher formants, the partials of the maskers were not resolvable in the auditory periphery, since their maximum spacing (the spacing of the harmonics of $140 \mathrm{~Hz}$ near $1700 \mathrm{~Hz}$ ) was about 1.5 semitone, whereas the bandwidth of the peripheral auditory filters is probably not less than 2 semitones for frequencies above $1000 \mathrm{~Hz}$ (Patterson \& Moore, 1986). Therefore, in the frequency regions that were critical for the vowels' identification, neighboring auditory filters probably responded very similarly (in terms of both average activity and temporal structure of 
the activity) to a given masker. Presumably, the tonotopic position of the auditory filter that is maximally excited by a vibrated vowel formant changes as a function of time, whereas a fixed formant maximally activates a fixed filter. However, an unmasking effect of vibrato through variations across filters of the formant-to-masker intensity ratio cannot occur if the filters are similarly excited by the masker.

Admitting that the unmasking effect of vibrato found in Experiment 2 was a sensory and central phenomenon, one is led to consider it as a Gestalt effect. In this respect, two different hypotheses are possible. First, the vibrato effect may be considered as an auditory illustration of the "common fate" rule: The common frequency modulation of the vowels' formants would have favored their grouping into a single "sound image" (McAdams, 1984) or "sound entity" (Hartmann, 1988). Second, it is possible that subjects were actually not sensitive to the coherence (parallelism) of the vowel formants' modulations and that these modulations aided identification only by creating local contrasts between spectral regions corresponding to a formant and adjacent regions dominated by the steady masker; the operative Gestalt factor would thus be similarity rather than common fate. At first sight, a valuable test of these two hypotheses seems to be an experiment in which the maskers are steady pulse trains and the vowels are made up of incoherently modulated formants. However, a serious difficulty would arise from the fact that modulating a vowel's spectral components in an incoherent manner necessarily results in momentary inharmonicities of that vowel; by themselves, such inharmonicities may have a negative effect on the perceptual integration of the vowel components (see Broadbent \& Ladefoged, 1957; Darwin, 1981, Experiment 4; Gardner et al., 1989).

Of course, if some Gestalt factors are indeed responsible for the unmasking of the vibrated vowels in Experiment 2 , it is likely that the same Gestalt factors are also responsible for the unmasking of the steady vowels in Experiment 3, where vibrated maskers were used.

In order to explain why vibrato had an effect on identification performance when the maskers were pulse trains (Experiments 2 and 3 ) but no effect when they were bursts of pink noise (Experiment 1), it must be pointed out that the response of an auditory filter to pink noise is certainly quite different from its response to both steady and vibrated formants: The waveform of a (voiced) formant has a periodic (or quasiperiodic) amplitude envelope, whereas such is not the case with a filtered noise. Presumably, vibrato played no role in Experiment 1 because periodicity cues were sufficient to segregate the vowels from the noise. By contrast, the response of an auditory filter to a pulse train can certainly be quite similar to its response to a vowel formant; in Experiments 2 and 3, this allowed Gestalt cues based on vibrato a good opportunity to play some role.

It seems more difficult to explain why vibrato affected thresholds only for $40-\mathrm{dB}$ maskers and in untrained listeners. However, a simple hypothesis on the origin of both effects can be drawn from an introspective observation made by each of the 3 trained listeners. They felt that it was impossible to tell if a vowel was vibrated or not near its identification threshold. It can thus be surmised that in Experiments 2-5, vibrato had no influence when, and because, the vowels were identifiable at a level for which their vibrato was not detectable. This hypothesis is consistent with the fact that in Experiments 2-5, thresholds were always better when vibrato had no influence than when it did matter. Thresholds below $-12 \mathrm{~dB}$ were obtained in the two experiments involving trained listeners and also when the maskers were at $65 \mathrm{~dB}$ in Experiments 2 and 3 ; by contrast, thresholds were about -7 or $-8 \mathrm{~dB}$ when an effect of vibrato was observed.

For an unmasked pure tone of $250 \mathrm{~Hz}$, of moderate level and long duration, the just-noticeable $6-\mathrm{Hz}$ vibrato has a peak-to-peak width of about $1.4 \%$ (Demany \& Semal, 1989). The vibrato width used in the present experiments $(6 \%)$ was four to five times larger. However, Zwicker and Graf (1987) showed that for a pure tone masked by noise, the detectability of vibrato is impaired as long as the level of the tone is less than about $25 \mathrm{~dB}$ above its masked threshold. For short-duration $(80-\mathrm{msec})$ harmonic complex tones partially masked by noise, Carlyon and Stubbs (1989) indicate that the just-noticeable vibrato width (for a $12.5-\mathrm{Hz}$ vibrato) can be as large as $12 \%$. We selected a vibrato width of $6 \%$ in order to mimic the "natural" vocal vibrato (Seashore, 1938/1967). Employing a markedly wider vibrato would have been problematic, since it would have probably impaired the subjects' phonetic categorization of the vibrated vowels. But given the detection thresholds just quoted, it seems quite reasonable to posit that in Experiments 2-5, vibrato played no role when and because it was simply not detected.

Admittedly, one problem remains with respect to the results of Experiments 2 and 3. The just-mentioned hypothesis would imply that at their identification threshold for each masker level, and thus when equally identifiable, the vowels were more detectable when the maskers were at $40 \mathrm{~dB}$ than when they were at $65 \mathrm{~dB}$. Why should this be the case?-We have no answer.

Let us end on a pragmatic note and consider, in the light of our results, the possible unmasking benefit of vibrato for a singer surrounded by an orchestra. Clearly, such a benefit would be useful only when the orchestra is playing loud, since only then are special vocal efforts required. However, our results suggest that an eventual benefit of vibrato can be expected only if the orchestra is playing piano or pianissimo. Is it a mistake of Nature? Actually, recall that in our synthetic vibrated vowels, all partials had a steady amplitude. For natural vowels, vibrato induces amplitude modulations of the partials, since, when the partials are frequency-modulated, the spectral envelope is kept fixed or almost fixed (Sundberg, 1982). Of course, these induced amplitude modulations may increase the detectability of formants and thus intelligibility. 


\section{REFERENCES}

Bregman, A. S., \& Doehring, P. (1984). Fusion of simultaneous tonal glides: The role of parallelness and simple frequency relations. $\mathrm{Per}$ ception \& Psychophysics, 36, 251-256.

Broadbent, D. E., \& LAdefoged, P. (1957). On the fusion of sounds reaching different sense organs. Journal of the Acoustical Society of America, 29, 708-710.

Carlyon, R. P., \& StubBs, R. J. (1989). Detecting single-cycle frequency modulation imposed on sinusoidal, harmonic, and inharmonic carriers. Joumal of the Acoustical Society of America, 85, 2563-2574.

Chalikia, M. H., \& Bregman, A. S. (1989). The perceptual segregation of simultaneous auditory signals: Pulse train segregation and vowel segregation. Perception \& Psychophysics, 46, 487-496.

DARWIN, C. J. (1981). Perceptual grouping of speech components differing in fundamental frequency and onset-time. Quarterly Journal of Experimental Psychology, 33A, 185-207.

Demany, L., \& Semal, C. (1989). Detection thresholds for sinusoidal frequency modulation. Journal of the Acoustical Society of America, 85, 1295-1301.

GARDNER, R. B., DARWIN, C. J. (1986). Grouping of vowel harmonics by frequency modulation: Absence of effects on phonemic categorization. Perception \& Psychophysics, 40, 183-187.

Gardner, R. B., Gaskill, S. A., \& Darwin, C. J. (1989). Perceptual grouping of formants with static and dynamic differences in fundamental frequency. Journal of the Acoustical Society of America, 85, 1329-1337.

Hartmann, W. M. (1988). Pitch perception and the segregation and integration of auditory entities. In G. E. Edelman, W. E. Gall, \& W. M. Cowan (Eds.), Auditory function (pp. 623-645). New York: Wiley.

HoRI, Y. (1989). Frequency modulation characteristics of sustained /a/ sung in vocal vibrato. Journal of Speech \& Hearing Research, 32, 829-836.

MARIN, C. M. H., \& MCAdams, S. (in press). Segregation of concurrent sounds: II. Effects of spectral envelope tracing, frequency modulation coherence, and frequency modulation width. Journal of the Acoustical Society of America.

MCADAMs, S. (1984). The auditory image: A metaphor for musical and psychological research on auditory organization. In W. R. Crozier \& A. J. Chapman (Eds.), Cognitive processes in the perception of art (pp. 289-323). Amsterdam: North-Holland.

MCADAMS, S. (1989). Segregation of concurrent sounds: I. Effects of frequency modulation coherence. Journal of the Acoustical Society of America, 86, 2148-2159.

MCADAMS, S., \& RoDET, X. (1988). The role of FM-induced AM in dynamic spectral profile analysis. In $\mathbf{H}$. Duifhuis, J. W. Horst, \&
H. P. Wit (Eds.), Basic issues in hearing (pp. 359-367). New York: Academic Press.

MCFADDEN, D. (1989). Spectral differences in the ability of temporal gaps to reset the mechanisms underlying overshoot. Journal of the Acoustical Society of America, 85, 254-261.

Patterson, R. D., \& Moore, B. C. J. (1986). Auditory filters and excitation patterns as representations of frequency resolution. In B. C. J. Moore (Ed.), Frequency selectivity in hearing (pp. 123-177). London: Academic Press.

SCHEFFERS, M. T. M. (1983). Sifting vowels: Auditory pitch analysis and sound segregation. Unpublished doctoral dissertation, University of Groningen, The Netherlands.

Schwartz, J. L., \& Escudier, P. (1989). A strong evidence for the existence of a large-scale integrated spectral representation in vowel perception. Speech Communication, 8, 235-259.

SEAShORE, C. E. (1967). Psychology of music. New York: Dover. (Original work published 1938)

SUNDBERG, J. (1977). Vibrato and vowel identification. Archives of Acoustics (Polish Academy of Sciences), 2, 257-266.

Sundrerg, J. (1982). Perception of singing. In D. Deutsch (Ed.), The psychology of music (pp. 59-98). New York: Academic Press.

ZWICKER, E., \& GRAF, L. (1987). Modulationsschwellen bei Verdeckung. Acustica, 64, 148-154.

\section{NOTES}

1. This vowel was the steady version of $/ \varpi /$. In Experiments 2 and 3 , the same vowel was responsible for the rejection of a subject's data in four cases out of six. It seems that the synthesized / $/$ / was somewhat less "natural," less "prototypical," than the other vowels used.

2. Let us remark here that in our experiments, main effects of vowel category or interactions involving this factor may originate, at least in part, from mere response biases. For instance, if a subject tends to select the response " $e$ " $(/ \varnothing /)$ on trials where he or she has in fact no idea of the presented vowel, correct identifications by chance will be more frequent for $/ ø /$ than for the other vowels; therefore, the identification threshold for $/ g /$ will be underestimated. This is why we do not attach importance to the effects of vowel category on identification thresholds.

3. A more "peripheral" explanation can also be proposed, since a similar effect of onset delay on masking has been found in experiments where the subject's task was simply to detect a sine tone pulse (for a recent review of data and hypotheses concerning this "overshoot" effect, see, e.g., McFadden, 1989).

(Manuscript received December 12, 1989; revision accepted for publication June 6,1990 .) 